courteous reply will be given. I would just add there is little good in supposing that Members of Parliament will be guided by what I alone write to them. The Member of Parliament wishes to know, not what I alone say, but what his constitutents want. If the majority of practitioners in each constituenoy in the United Kingdom write to their M.P. to oppose the Bill, then no Bill can pass.

In 1894 eight medical societies and nine branches of the British Medical Association, comprising 3324 practitioners, voted against Registration of Midwives, and only 392 for. In 1895 the anvual meeting of the British Medical Association passed a very strong resolution against the proposal; and in 1896 the Council of the Association resolved :-

"1. The Bill practically abrogates the existing Medical Acts as regards the practise of midwifery. 2. That it is fraught with danger to the public, inasmuch as it contemplates the creation of an inferior order of practitioners to attend upon the poor. 3. That it is unjust to medical profession, inasmuch as it proposes to register an inferior order of practitioners, instead of a body of well-qualified midwifery

"Resolved :- That the Council be requested to prepare a petition for presentation to the House of Commons embodying reasons against

Mr. F. Fowke informs me Sir W. Foster presented the petition, May, 1896. In an editorial in THE LANCET ${ }^{2}$ reference is made to a midwife who operated upon an infant, it bleeding to death, and where it is stated :- "Midwives are of great value to a community when it is fully recognised that they are specially trained nurses and nothing more." I shall be glad to hear from any practitioners willing to do their duty and who have received promises of support.

I am, Sirs, yours truly,

ROBERT R. RENTOUE.

Hartington-road, Liverpool, Feb. 14th, 1897.

\section{MR. LOCH AND THE ABUSE OF HOSPITALS.} To the Editors of THE LANCET.

SIRs, - I feel confident that the thousands and tens of thousands interested in the welfare and progress of our hospitals-everyone working for them without fee or reward, as well as those receiving for their services far less than a hiving wage-and the millions of people too poor to pay for help in sickness, or in consequence of accidental injury, in all parts of the world, will join in begging $\mathrm{Mr}$. Loch and his Friends to abstain from further interference with regard to the so.called "abuses" of hospitals and other medical charities during this one year-1897-only. In 1898 we may fully discuss and, I hope, finally settle many of the important and interesting questions again brought forward in his letter to the Times of Feb. 12th, 1897, and in other commuaications with greater freedom and at more leisure than is at this time possible, without fear of damaging the financial interests of our hospitals and other institutions founded and supported for the benefit of our sick poor, and without any risk of wounding the susceptibilities of those whose love of their hospitals is of life-long duration.

For these and some other reasons $I$ think it better to postpone the observations I desire, with your permission, to bring before the profession with reference to the highly important and enormously complicated question of the best means of restoring to health in the shortest time people suffering from sudden, acute, or chronic maladies, who cannot possibly afford to pay for medical services and provide for the expenditure consequent upon inability to work. Many of my medical friends will, I am sure, gladly assist in the consideration of matters of such consequence, and as by that time I shall have completed fifty years of active and almost continuous hospital work I may also be permitted, without being accused of presumption, to bring before the orofession some of the views I have been led to form, which differ in many respects from those entertained by $\mathrm{Mr}$. Loch, and persistently adrocated by him for many years.

If, however, the organising enthusiasm of Mr. Loch and his friends renders a year's rest from their labours unbearable I venture to recommend during the interim an inquiry into a matter which might be undertaken with advantage, and which bears in some degree upon the causes of the complaints of practitioners in certain neighbourhoods who think that their interests have been seriously affected by the increasing popularity of the out-patient departments of our hospitals, though it seems probable that other circumstances have been operating at the same time and perhaps in greater degree to bring about the state of things which all of as so much regret. Among these must be included the fact of the enormous number of new remedies which have been intro duced during the last few years, and new methods of treat ment which are continually being pressed upon us. Medicines in the inviting form of tabloids, warranted to cure all soris of ailments, have been brought into public notice in all possible ways and at vast expense. Now it would be of great service to the public, the profession, and to the poor if the most usefal and the many worthless among these could be pointed out. Many have come to us from America and many from Germany; not a few have been found by some of us who have tried them to be of little use, and some positively inert; while a few coming, I think, from France, though, perhaps, made elsewhere, are too violent in their action, and some are uncertain. We desire very much to ascertain the truth with regard to the beneficial action or otherwise of many of these medicines with which we are inundated and which are too numerous to remember. Here then, is an inquiry useful to the public and the profession, and, at the same time, offering a wide field for the labour of those skilled in financial educational and statistical investigations of much importance in reference to hospital management and finance, for the cheapness of many of these medicines is, indeed, remarkable, and the small space they occupy would enable those skilled in organisation to establish small dispensaries everywhere for sale to the necessitous poor at a very cheap rate-say, a halfpenny for twelve doses and a halfpenny for the advice given. In time the dispensaries would become self-supporting, the out-patient departments of our hospitals would suffer in popularity, and ere long the great desire of Mr. Burdett-the extinction of the present system of treating multitudes of out patients in our hospitals - would be gratified.

Feb. 15th, 1897. I am, Sirs, your obedient servant,

LIONEL S. BEALE.

\section{"SHOULD EPILEPTICS MARRY?" \\ To the Elditors of THE LANCET.}

SIRS, - In THE LANCET of Feb. 13th Mr. Thistle asks, "Has Dr. Gowers any special reason for supposing that accidental lesions of the brain are less liable to be transmitted than similar lesions of the eye or the finger, instances of which are so frequently brought under our notice?" My answer is that I have no reason to believe it, but that no instance of the two examples he mentions has ever come under my notice directly or indirectly. Since it is the opinion of some of those who have given most attention to the subject that such transmission never occurs, Mr. Thistle should certainly pub. lish some of the instances that so frequently come under bis notice. An interesting letter appears in the last number of Nature, mentioning that Dr. Pritchard long ago anticipated very definitely the recent conclusions of Galton and Weissmann that such transmission of acquired characters does not occur. I am, Sirs, yours faithfully

Queen Anne-street, London, W., Feb. 15th, 1897. W. R. Gowens

\section{THE POSITION OF THE AURICULO- VENTRICULAR CUSPS DURING SYSTOLE. \\ To the Editors of THe LANCH.}

SIRs, - I have for some fifteen years been wondering why the theory attributed to Parchappe as to the action of the auriculo-ventricular valves is not taught in England, and during the last few weeks I have several times been made aware that it is generally unknown in this country. Now, since it explains cardiac sounds which are otherwise dificult to understand, and has been accepted by such men as Burdach, Purkinje, and more recently by Malherbe and Fossion, who have developed it, and J. Beclard, who admits it in the seventh edition of his "Physiology" (1880), surely it is time that every practitioner considered it. Marc Sée, in his "Researches on the Anatomy and Physiology of the Heart" (Paris, 1875), still further elaborates it, saying that the effect of the contraction of the musculi papillares, which takes place at the same time as that of the muscular walls of the 